\title{
Giant adrenocortical carcinoma with 27-month disease-free survival by surgical resection alone: $A$ case report
}

\author{
Martin Straka ${ }^{\mathrm{a}}$, Renata Soumarova ${ }^{\mathrm{b}}$, Jan Bulejcik ${ }^{\mathrm{c}}$, Martin Banik $^{\mathrm{d}}$, Mikulas Pura ${ }^{\mathrm{e}}$, Matej Skrovina $^{\mathrm{a}}$
}

\begin{abstract}
Background. Adrenocortical cancer (ACC) is a rare disease with an estimated incidence of 1-2/million/year. The tumour stage and completeness of surgical resection have the biggest impact on survival. Whereas stage I-II patients survive in $55-64 \%$ of cases, only $0-5 \%$ of patients with stage IV disease are still alive at 5 years. A median survival of 33 months can be expected after curative surgery. Incomplete surgery leads to a significant drop in survival.

Method. We present a 40-year-old man who underwent a technically demanding complete surgical excision of a giant $(26 \mathrm{~cm}, 2372 \mathrm{~g})$ ACC and experienced a 27-month disease-free survival without any systemic treatment. Detailed description of the surgical anatomy in relation to tumour size and patient body constitution is provided. The surgical strategy and exposure pitfalls under such extreme circumstances are discussed.

Conclusion. To achieve R0 resection in locally advanced disease, en bloc resection with neighbouring organs is widely recommended. Giant tumours may however pose a technical challenge due to space constraints.
\end{abstract}

Key words: adrenocortical carcinoma, adrenal tumour, surgical resection, disease-free survival

Received: January 21, 2013; Accepted: May 21, 2013; Available online: June 18, 2013

http://dx.doi.org/10.5507/bp.2013.040

${ }^{a}$ Department of Surgery, Comprehensive Cancer Centre, Hospital Novy Jicin, Novy Jicin, Czech Republic

${ }^{b}$ Department of Oncology and Radiotherapy, Comprehensive Cancer Centre, Hospital Novy Jicin, Novy Jicin

'Department of Vascular and Minimally Invasive Surgery, Hospital Podlesi, Trinec

${ }^{d}$ Department of Pathology, Comprehensive Cancer Centre, Hospital Novy Jicin, Novy Jicin

eDepartment of Endocrinology, National Institute of Endocrinology and Diabetology, Lubochna, Slovakia

Corresponding author: Martin Straka, e-mail: martin.straka@nemnj.cz

\section{INTRODUCTION}

Adrenocortical cancer (ACC) is a rare disease with a dismal prognosis ${ }^{1-3}$. Most ACCs are of sporadic origin, but the tumour may be a part of several congenital or familiar diseases ${ }^{4,5}$. The tumour presents as an overt clinical syndrome of hormonal hypersecretion or symptomatic abdominal mass ${ }^{5,6}$. The stage of the tumour and completeness of the surgical intervention are the main determinants of outcome $e^{4,7}$. Prognosis is highly stage dependent and over the years several staging systems have been proposed. Currently, the ENSAT (European Network for the Study of Adrenal Tumours) classification (2008) is commonly used ${ }^{8}$. Tumour size $5 \mathrm{~cm}$ defines stages I and II with a 5 years survival rate $84 \%$ and $63 \%$ respectively. Stage III tumour is either locally spread but does not infiltrate neighbouring organs or any size tumour with positive lymph nodes. Five-year survival for stage III patients is $51 \%$ (ref. ${ }^{9}$ ). Stage IV ACC invades neighburing organs or has fixed positive lymphnodes or distant metastases. For this stage, survival drops to $15 \%$ at 1 year $^{10}$. Complete surgical excision is achieved in 70$85 \%$ of cases and these patients have a median survival up to 74 months $^{6,7}$. Incomplete resection on the other hand, shrinks the median survival to 6-27 months ${ }^{11-13}$. It is important to know that most patients surviving at 5 years are not cured but alive with the disease and $85 \%$ of patients resected for cure will develop recurrence or distant metastases ${ }^{6,14}$. Other factors negatively influencing the outcome are size of the tumour (more than $12 \mathrm{~cm}$ ), high mitotic activity, necrosis, high expression of Ki-67and TP53 gene mutation positivity ${ }^{15-17}$. Surgical excision represents the mainstay of treatment and is indicated even in selected patients with stage IV disease $e^{6,18,19}$. Specific treatment with the adrenolytic agent mitotan is widely discussed elsewhere. Although considered as a reference treatment with a response rate of $30 \%$, the drug has serious side- effects, which may limit its use in some patients. Plasma concentration has to be monitored closely as there is a narrow therapeutic range ${ }^{6,9,19}$. Two combinations of mitotan and cytotoxic agents were studied recently. These are the Berruti protocol with etoposid, doxorubicin, cisplatin (EDP) in combination with mitotan and a combination of streptozocin with mitotan. EDP plus mitotan was found to be superior to mitotan plus streptozocin in the FIRM-ACT study group randomized study published this year. Median survival to progression for the EDP plus mitotan group was longer. However overall survival was not significantly different (14.2 vs. 12 months) (ref. ${ }^{20}$ ). Overall, systemic treatment of ACC is unsatisfactory to date ${ }^{19}$.

\section{CASE REPORT}

A 40-year-old, obese (BMI $32.7 \mathrm{~kg} \cdot \mathrm{m}^{-2}$ ), Caucasian man was admitted to ICU in October 2009 after 14 days of respiratory distress. The patient's history included the 


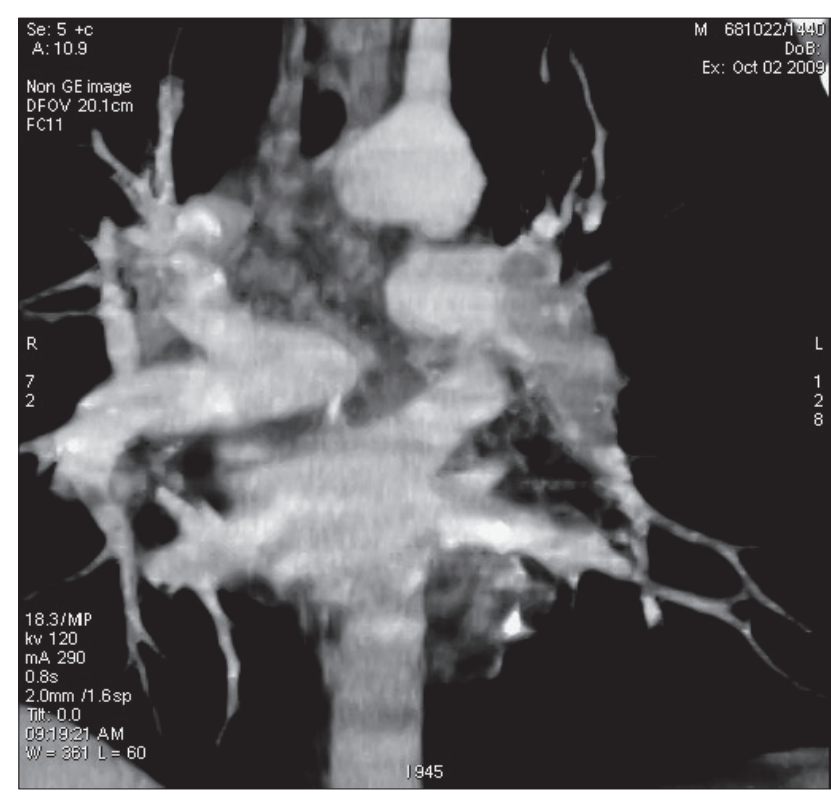

Fig. 1. CTA image with thrombus in pulmonary artery.

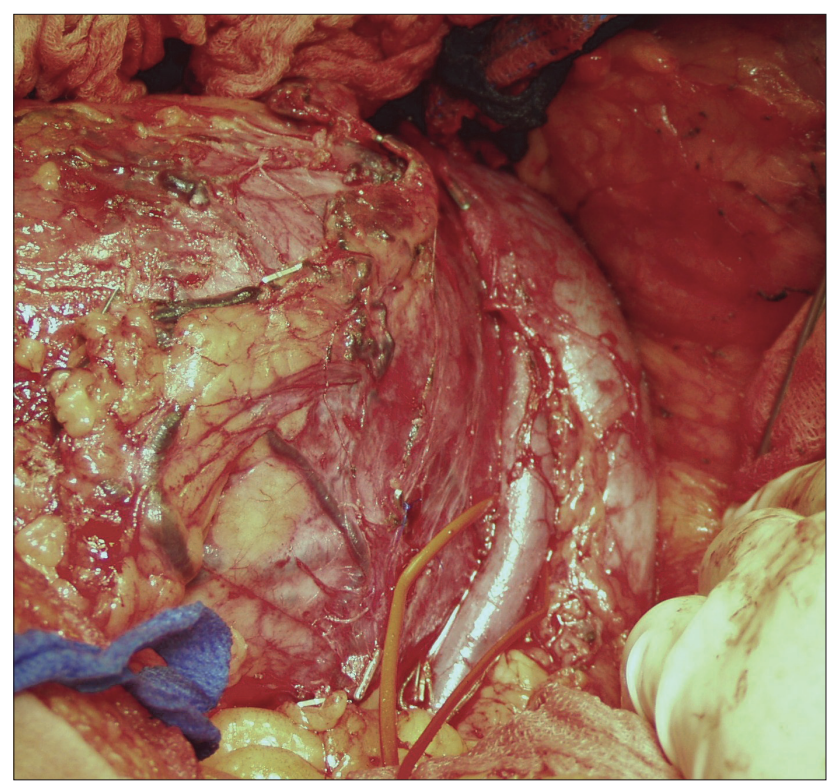

Fig. 3. Intraoperative view, right renal vein taped, inferior vena cava displacement by infrahepatic portion of the tumour can be seen.

death of his father due to pulmonary embolism, apendectomy in the past, hypertension and alcohol abuse medically treated. Brochoscopy was negative, echocardiography showed right ventricular dilatation and pulmonary hypertension, computerized tomographic angiography (CTA) scans revealed massive pulmonary embolism (Fig. 1). Anticoagulant treatment was started and the patient's condition improved. A giant right hypochondrium tumour with severe right kidney and inferior vena cava (VCI) displacement was shown to be an underlaying cause of embolism (Fig. 2). An inferior vena cava filter placement procedure was discussed with both interventional radiologist and vascular surgeon, but was considered technically not feasible due to VCI angulation. Patient went on

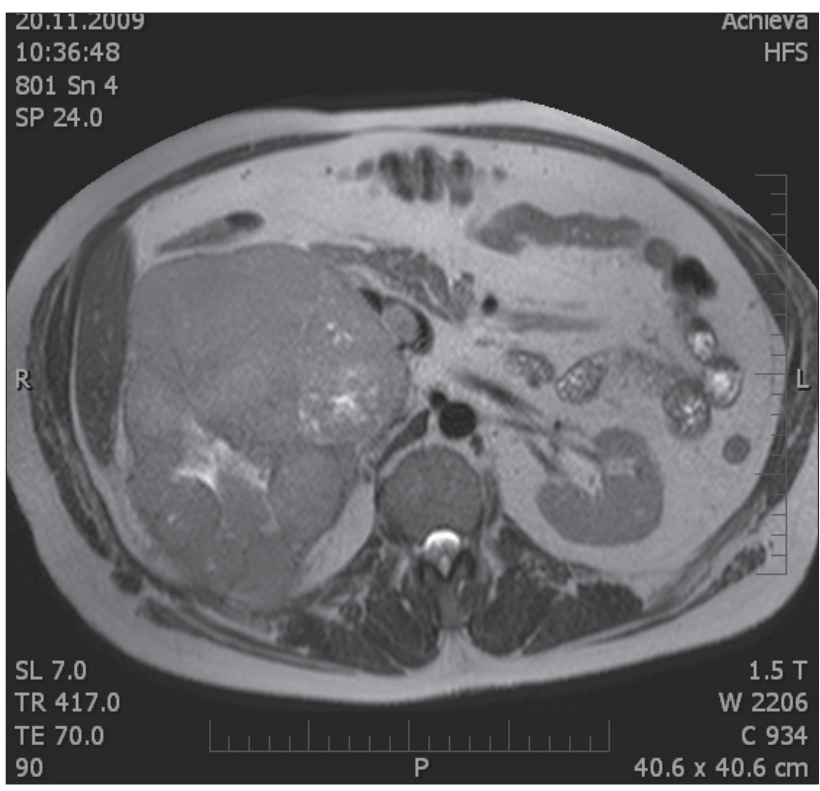

Fig. 2. MRI T2 axial image showing caudal portion of the tumour and VCI thrombus before anticoagulant treatment.

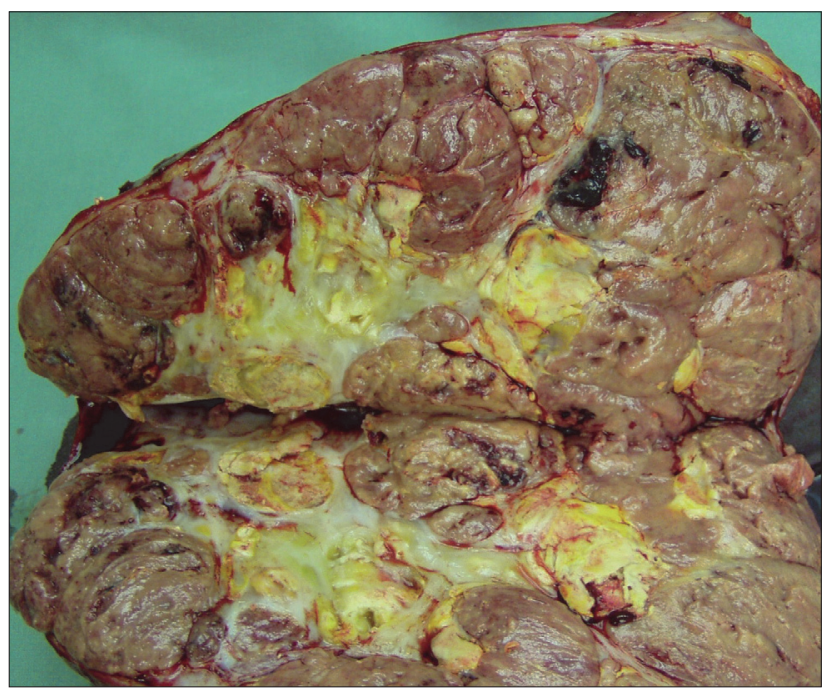

Fig. 4. Specimen $2372 \mathrm{~g}(26 \times 16 \times 13 \mathrm{~cm})$, gross appearance on section.

with anticoagulant treatment and further investigations were carried out. Neuron specific enolase (NSE) level of $97.8 \mathrm{ug} / \mathrm{L}$ was positive and a diagnosis of suprarenal gland adenoma was suggested based on percutaneous biopsy. Being aware of the high risk that adrenal gland carcinoma might be in fact involved, distant metastases were excluded and surgical exploration was planned. The overall condition of the patient allowed for planed surgery not sooner than 01.2010. Due to the patient's body constitution, thoracophrenolaparotomy had to be made to approach the tumour. Even this wide exposure did not enable handling the tumour conveniently. Every effort was made to deliberate the right kidney without sacrifying its vasculature. Here, especially the right renal vein pres- 


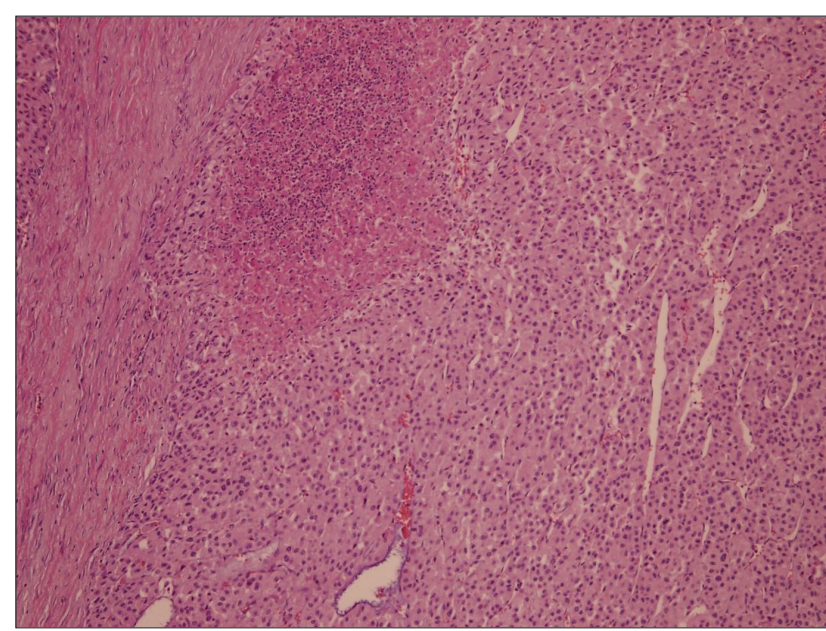

Fig. 5. Adrenal carcinoma, hematoxylin and eosin stain (200x). Area of necrosis.

ervation was demanding due to extensive distortion and pressure from the tumour (Fig. 3). Several collateral veins draining to the right renal vein had to be secured. After right kidney mobilization, displaced VCI was carefully detached from the tumour, without any direct involvement found. The most problematic part of the excision turned out to be the right hepatic lobe and retrohepatic VCI detachment. The option of liver hanging maneuver with en bloc right hepatectomy was considered, but this was abandoned (this will be discussed later). Right lobe detachment was complicated by $4000 \mathrm{~mL}$ of blood loss due to venous collateral hemorrhage, which was hard to control despite suprarenal VCI clamping. Due to the size of the tumour, the right suprarenal vein could not be approached until the very end of the dissection. The tumour was excised without capsule violence and R0 resection was achieved (Fig. 4). Tumour met Weiss and van Slooten ACC criteria, with several negative prognostic factors: high nuclear grade 3-4, intratumoral necrosis, vascular invasion, tumour capsule infiltration, mitotic activity $7 / 50$ HPF, Ki 67 positivity (12\%) (Fig. 5 and 6). No residual VCI thrombosis during the surgery was found and no direct damage to the vessel occured. Despite this a caval filter for infrarenal incomplete thrombosis was inserted postoperatively and excessive manipulation with VCI could be responsible for this. Neither in the postoperative, nor in the follow-up period did any any pulmonary embolism attack occur. The patient was discharged after prolonged wound healing period with vacuum-assisted healing device.

The medical oncologist and endocrinologist followed the patient for the next 27 months. No adjuvant treatment was initiated. The patient had repeated Positron Emission Tomography Computed Tomography (PET/CT) scanning to diagnose disease recurrence early. In March 2012 scanning revealed pathological 18-fluorodeoxyglucose (FDG) accumulation in the interaortocaval lymph nodes as a sign of disease progression. In June 2012 an attempt at radical extirpation was made, but confluent malignant lymphnodes with invasion to retroperiotneal structures were found and further excision abandoned. To

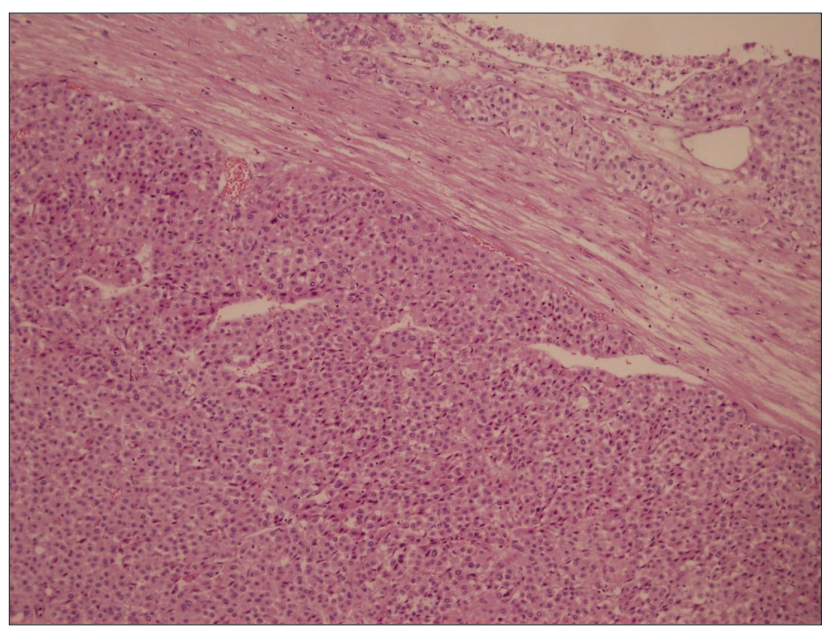

Fig. 6. Adrenal carcinoma, hematoxylin and eosin stain (200x). Capsular invasion.

time, the patient survived 36-month with surgical excision of primary tumour alone.

\section{DISCUSSION}

Several issues concerning surgical startegy and adjuvant therapy need to be discussed. First, the option of en bloc right hepatectomy. In large tumours, there is a universally accepted approach of en bloc resection of ACC with neighbouring organs, demonstrated by several authors ${ }^{10,17,18}$. This ensures not only R0 resection in case of questionable local tumour infiltration, but it also prevents blood loss from pathological collateral vessels. Elimination of the blood loss and tumour cell seeding is of paramount importance in ACC excision. En bloc resection with right kidney and right hepatic lobe in case of right sided lesion may in fact be technically easier and oncologically safer. According to the literature, the average tumour size at the time of surgery is $800 \mathrm{~g}$, or 12 $\mathrm{cm}$ in diameter ${ }^{10}$. Giant tumours, such as was the case here, impose specific operating field constraints. Under extreme conditions, such as a patient with high BMI and $2372 \mathrm{~g}$ tumour $(26 \times 16 \times 13 \mathrm{~cm})$, thoracophrenolaparotomy is done to expose the field adequately. Bearing in mind, that the right lobe detachment/resection is going to be the most demanding and risky part of excision, we detached the right kidney, all lateral aspects of the tumour and retroperitoneal fat, secured VCI above the renal veins. The tumour was left attached to the right lobe and retrorepatic VCI only, with no option of early right suprarenal vein division. To that point virtually no blood loss was encountered. The option of liver hanging maneuver with en bloc right hepatectomy was considered but this was abandoned because the retrohepatic VCI course was distorted and the risk of uncontrolled hemorrhage was high. An anterior approach could be used without liver hanging and this option we judged repeatedly during the procedure, but the space we were able to create in the operating field we did not consider adequate for safe parenchymal transsection with an anticipation of the hardest part in 
the very end of the dissection. The risk of uncontrolled hemorrage without prior liver hanging we evaluated as unacceptable. Not doing this however, resulted in extremely high blood loss which we were trying to avoid in the first instance. Retrospectively, we admit that the decision not to resect the right lobe en bloc with the tumour was not right. In the light of our negative experience under such extreme circumstances liver hanging maneuver with prior suprahepatic/intrapericardial and suprarenal VCI control probably could minimize the blood loss as described by Japanesse authors in cases where VCI resection was necessary $^{18}$. We achieved R0 without tumour capsule violation without en bloc liver resection, but at the price of a considerable blood loss.

Thrombosis of VCI and consequent pulmonary embolism as a first tumour presence symptom we considered to be malignant (i.e. tumour embolism). As no direct tumour infiltration to VCI was found, anticoagulant treatment led to complete resolution of the thrombus and no thrombosis was found at the time of operation, we found tumour pressure and severe VCI dislocation to be a cause of thromboembolism rather than malignant nature of the disease in this particular case. Even if we had not noticed any direct damage to VCI during the disection, manipulation with the vessel was excessive and could lead to formation of small infrarenal thrombus in the postoperative period.

Systemic treatment of ACC is unsatisfactory to date. In our particular case, systemic adjuvant treatment was abandoned both due to patient non-compliance (alcohol abuse) and prolonged wound healing. As the lymph node disease progression in June 2012 was found inoperable, the patient was offered paliative radiotherapy. This modality had technical limits given by the immediate presence of radiosensitive tissues in the past. These days the issue is revisited and the use of conformal radiotherapy or intensity-modulated radiation therapy (IMRT) made radiotherapy valuable option in a palliative setting ${ }^{21}$.

\section{CONCLUSION}

Surgical excision of ACC should be offered to every fit patient in stage I-III and carefully considered for selected patients with stage IV disease. Resection of large ACC can be a technical challenge. Wide exposure and enbloc resection should be considered in cases of locally advanced disease. Vascular control should be attempted in any case where massive blood loss can be expected. Not doing so may result in life threatenig blood loss and uncontrolled intraoperative hemorrage. Our (negative) experience supports general recommendation to resect the lesion en bloc whenever there is a close relationship to neighbouring organs. This might be true regardless of extreme operating space constriants in giant tumours. Even in cases when systematic therapy with mitotan is contraindicated, radical surgery alone may lead to considerable survival benefit.

\section{ACKNOWLEDGEMENT}

Authorship contributions: MSt: manuscript writing MSt, RS: literature search RS: onlology consult and follow-up MB: histopathology and figures MP: endocrine consult and follow-up MSt, RS, JB, MP, MSk: final approval.

Conflict of interest statement: None declared.

\section{REFERENCES}

1. Reibetanz J, Kroiss M, Deutschbein T, Fenske W, Gasser M, Jurowich C, Germer CT, Allolio B, Fassnacht M. [German adrenocortical carcinoma registry. Surgical therapy results and follow-up treatment.] [Article in German] Chirurg 2012;83:528-35.

2. National Cancer Institute PDQ.General Information About Adrenocortical Carcinoma [online]. 2012 Nov [cited 2012 Nov 24]. Available from:http://www.cancer.gov/cancertopics/pdq/treatment/adrenocortical/HealthProfessional

3. Allolio B, Fassnacht M. Clinical review: adrenocortical carcinoma: clinical update. J Clin Endocrinol Metab 2006;91:2027-37.

4. Pura M. [Adrenocortical cancer]. In: Pacák K, Lazúrová I, editors. [Endocrinetumors of adrenal gland in currentclinical practice]. Praha: Galén; 2011. p. 174-99. [Article in Slovak]

5. Bertagna X, Groussin L, Abiven G, Bertherat J. Adrenal cortical carcinoma: clinical management. In: Bertagna X, editor. Adrenal cancer. Montrouge: Éditions John Libbey Eurotext; 2006. p. 1-12.

6. Schulick RD, Brennan MF. Long-term survival after complete resection and repeat resection in patients with adrenocortical carcinoma. Ann Surg Oncol 1999;6:719-26.

7. Lombardi CP, Raffaelli M, Boniardi M, De Toma G, Marzano LA, Miccoli P, Minni F, Morino M, Pelizzo MR, Pietrabissa A, Renda A, Valeri A, De Crea C, Bellantone R.Adrenocortical carcinoma: effect of hospital volume on patient outcome. Langenbecks Arch Surg 2012;397:2017.

8. Lughezzani G, Sun M, Perrote P, Jeldres C, Alasker A, Isbabarn $H$, Budäus L, Shariat SF, Guazzoni G, Montorsi F, Karakiewicz PI. The European Network for the Study of Adrenal Tumors is prognostically superior to the international union against cancer-staging system: A North American validation. Eur J Cancer 2010;46:713-9.

9. Fassnacht M, Allolio B. Clinical management og adrenocortical carcinoma. Best Pract Res Clin Endocrinol Metab 2009;23:273-89.

10. Dousset B, Gaujoux S, Thillois JM. Surgical treatment of adrenal cortical carcinoma. In: Bertagna X, editor. Adrenal cancer. Montrouge: Éditions John Libbey Eurotext; 2006. p. 71-95.

11. Harrison LE, Gaudin PB, Brennan MF. Pathologic features of prognostic significance for adrenal cortical carcinoma after curative resection. Arch Surg 1999;134:181-5.

12. Icard $P$, Goudet $P$, Charpenay $C$, Andreassian $B$, Carnaille $B$, Chapuis $Y$, Cougard $P$, Henry JF, Proye C.Adrenocortical carcinomas: surgical trends and results of a 253-patient series from the French Association of Endocrine Surgeons study group. World J Surg 2001;25:891-7.

13. Vassilopoulou-Sellin R, Schultz PN. Adrenal cortical carcinoma. Clinical outcome at the end of the 20th century. Cancer 2001;92:11321.

14. Pommier RF, Brennan MF. An eleven-year experience with adrenocortical carcinoma. Surgery 1992;112:963-71.

15. Stojadinovic A, Ghossein RA, Hoos A, Nissan A, Marshall D, Dudas M, Cordon-Cardo C, Jaques DP, Brennan MF. Adrenocortical carcinoma: clinical morphologic, and molecular characterization. J Clin Oncol 2002;20:941-50.

16. Assié G, Guillaud-Bataille M, Ragazzon B, Bertagna X, Bertherat J, Clauser $\mathrm{E}$. The pathophysiology, diagnosis and prognosis of adrenocortical tumors revisited by transcriptome analyses.Trends Endocrinol Metab2010;21:325-34.

17. Morimoto $R$, Satoh $F$, Murakami O, Suzuki T, Abe T, Tanemoto M, Abe M, Uruno A, Ishidoya S, Arai Y, Takahashi K, Sasano H, Ito S.Immunohistochemistry of a proliferation marker Ki67/MIB1 in ad- 
renocortical carcinomas: Ki67/MIB1 labeling index is a predictor for recurrence of adrenocortical carcinomas. Endocr J 2008;55:49-55.

18. Ohwada S, Izumi M, Tanahashi Y, Susumu Kawate, Hamada K, Tsutsumi H, Horiguchi J, Koibuchi Y, Takahashi T, YamadaM. Combined liver and inferior vena cava resection for adrenocortical carcinoma. Surg Today 2007;37:291-7.

19. Gaujoux S, Al-Ahmadie H, Allen PJ, Gonen M, Shia J, D'Angelica M Dematteo R, Fong Y, Blumgart L, Jarnagin WR. Resection of adrenocortical carcinoma liver metastasis: is it justified? Ann Surg Oncol 2012;19:2643-51.
20. Fassnacht M, Terzolo M, Allolio B, Baudin E, Haak H, Berruti A, Welin S, Schade-Brittinger C, Lacroix A, Jarzab B, Sorbye H, Torpy DJ, Stepan V, Schteingart DE, Arlt W, Kroiss M, Leboulleux S, Sperone $P$, Sundin A, Hermsen I, Hahner S, Willenberg HS, Tabarin A, Quinkler $M$, de la Fouchardière $C$, Schlumberger $M$, Mantero $F$, Weismann $D$, Beuschlein F, Gelderblom H, Wilmink H, SenderM, Edgerly M, Kenn W, Fojo T, Müller HH, Skogseid B;FIRM-ACT Study Group. Combination chemotherapy in advanced adrenocortical carcinoma. N Engl J Med 2012; 366:2189-97.

21. Milgom SA, Goodman KA. The role of radiation therapy in the management of adrenal carcinoma and adrenal metastases. J Surg Oncol 2012;106:647-50 